\title{
TFP change and its components for Swedish manufacturing firms during the 2008-2009 financial crisis
}

\author{
Pontus Mattsson $\mathbb{1}^{1}$ - Jonas Månsson ${ }^{1}$ - William H. Greene ${ }^{2}$
}

Published online: 26 October 2019

(c) The Author(s) 2019

\begin{abstract}
A driving force of economic development is growth in total factor productivity (TFP). Manufactured goods are, to a large extent, exports, and represent an important part of the economy for many developed countries. Additionally, a slowdown in labour productivity has been observed in many OECD countries since the financial crisis of 2008-2009. This study investigates TFP change and its components for the Swedish manufacturing industry, compared with the private service sector, during the years 1997-2013, centering on the financial crisis. Stochastic frontier analysis (SFA) is used to disentangle persistent and transient efficiency from firm heterogeneity and random noise, respectively. In addition, technical change (TC), returns to scale (RTS) and a scale change (SC) component are also identified. Along with the empirical analysis, an elaborative discussion regarding TC in SFA is provided. The persistent part for manufacturing (service) is $0.796(0.754)$ and the transient part is $0.787(0.762)$, indicating improvement potentials. Furthermore, TFP change is substantially lower between the years 2007-2013, compared to 1997-2007. This occurs due to a lower technological progress. Policy should, therefore, target interventions that enhance technology. However, care needs to be taken so that policies do not sustain lowproductive firms that otherwise would exit the market.
\end{abstract}

Keywords Financial crisis $\cdot$ Manufacturing $\cdot$ Persistent and transient efficiency $\cdot$ Technical change $\cdot$ Total factor productivity

JEL classification $\mathrm{C} 23 \cdot \mathrm{D} 24 \cdot \mathrm{O} 14 \cdot \mathrm{L} 25 \cdot \mathrm{L} 60 \cdot \mathrm{L} 80$

\section{Introduction}

Total factor productivity (TFP) is the major determinant of economic growth (Krugman 1997) and particularly important for export-dependent countries. The reason for this essentiality is that high operation efficiency and technology development are necessary for competitiveness in an international market. A slowdown in labor productivity growth can be observed in a large share of the industrialized countries and Sweden performed worse than other OECD countries after 2007 (OECD 2015). Moreover, the productivity difference within sectors has increased according

Pontus Mattsson

pontus.mattsson@lnu.se

1 Department of Economics and Statistics, Linnaeus University, 351 95 Växjö, Sweden

2 Department of Economics, Stern School of Business, New York University, New York, NY, USA to Andrews et al. (2016). Furthermore, potential catch-up after a financial crisis is of particular importance because Cerra and Saxena (2008) showed that the per capita income ranking has fell for several countries after a financial crisis, e.g. for Sweden after the banking crisis in the early 1990s. Even though TFP is a driving force for economic growth that is likely to be affected during economic downturns-it has hardly been investigated during the financial crisis 2008-2009 and the following period.

The manufacturing sector is of specific importance, due to its export dependence and potential for spill-over into other sectors (Kaldor 1966). In addition, several studies show that negative TFP shocks within manufacturing are the primary cause of economic stagnations (see e.g., Fukao and Kwon 2006). Sweden went from one of the weakest countries, (in terms of labor productivity) within the OECD area to being one of the strongest during the period 1992-2002, which Oh et al. (2012) analyzed. In the early 1990s, Sweden abandoned the fixed exchange rate, which is, at least partly, the explanation for the increase in competitive power during this period (Bergvall 2002). 
The aim of this paper are: (a) to examine TFP and its decomposed factors before, during and after the financial crisis in 2008-2009; (b) to analyse the level of technical efficiency. A four-component stochastic frontier model (SFM) for the Swedish manufacturing industry is applied for the period 1997-2013, which permits analysis of a potential catching-up following the crisis. For comparison purpose, the domestic service sector is incorporated in the analysis since it, potentially, is less affected by changes in world demand. Additional to the empirical analysis, a question is raised regarding interpretation of $\mathrm{TC}$ in stochastic frontier analysis (SFA).

To investigate and compute TFP and its components, we use the SFM that was simultaneously proposed by Colombi et al. (2014), Kumbhakar et al. (2014) and Tsionas and Kumbhakar (2014). In this model, inefficiency is decomposed into a persistent and a transient component separated from firm-heterogeneity and random noise, respectively. This separation is interesting of several reasons. First, productivity differences are shown to be increased by Andrews et al. (2016), which is closely related to the topic of efficiency in SFA. Second, it gives insights whether firms with a low level of persistent efficiency drop out from the market after the financial crisis. Third, the transient part of efficiency would become lower if existing firms perform worse during and after the financial crisis. Additionally, technical change (TC), returns to scale (RTS) and a scale change (SC) component are also identified. The TFP change is obtained as the sum of TC and SC, where TC represent a shift of the production function and $\mathrm{SC}$ indicates movements towards or away from optimal scale. To be noted is that this type of identification procedure does not separate the change of technical efficiency from TC as performed in, for example, Bauer (1990).

Our findings show improvement potentials in efficiency. The persistent part for manufacturing (service) is 0.796 (0.754) and the transient part 0.787 (0.762). Both the manufacturing and the private-service sector had a decline in efficiency during the financial crisis, but it was smaller for the service sector. During the post-crisis period, firms within both sectors caught up to the level of efficiency they had before. Furthermore, the manufacturing (service) had an annual average TFP growth of $1.17 \%$ (1.24\%) measured over the whole period. However, substantial differences are observed in TFP change over time when separating the time-periods; i.e., 1997-2007 and 2007-2013, respectively. The manufacturing sector has a TFP growth of $1.98 \%$, and the service sector, $1.80 \%$, during the former period, i.e. before the crisis. This can be compared with 0.44 and $0.54 \%$ in the latter. This difference between the pre- and post-periods is statistically significant on the $1 \%$ level. However, it should be stated that a causal interpretation between the financial crisis and a lower TFP growth cannot

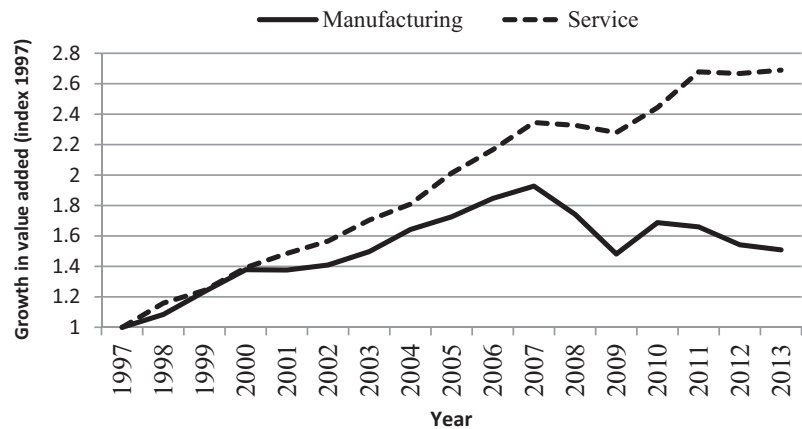

Fig. 1 Development of value added in the manufacturing and service ${ }^{1}$ sectors

be made. Additionally, a pure separation, whether this is driven by inefficient firms or frontier firms, cannot be performed, i.e. the production function can be pushed towards the origin by inefficient firms. Nevertheless, for manufacturing, the lower transient efficiency during the financial crisis can still be observed when time is indicated by year fixed effects, meaning that firms with low efficiency affect TC, at least, to some extent. However, due to the lower TC during 2007-2013, policy makers should target interventions that enhance technology, e.g., increasing the attractiveness of innovating. In addition, care should be taken when designing these policies so they do not sustain lowproductive firms that would otherwise close down.

The remainder of the paper is organized as follows. The background of this study is presented in Section 2. In Section 3, different ways of measuring efficiency and TFP, with a focus on stochastic frontier models and interpretation, are described. The methodology used in this paper is presented in Section 4. Section 5 considers the data, and the results are presented in section 6 . Finally, section 7 concludes and provides policy recommendations. ${ }^{1}$

\section{Background}

Data from OECD on labor productivity suggests that Sweden was lower in comparison to other countries during the period 2007-2013 (OECD 2015). A description of the development of the aggregated value added in the included sectors, standardized in 1997, during the studied period, is shown in Fig. 1.

Figure 1 indicates a steady growth of aggregated value added with the exception of the period 2000-2002 for manufacturing. Corresponding to the period during the financial crisis, both sectors indicate a decline that is steeper for manufacturing. However, the service sector continues to increase after the small decline while the aggregated value

\footnotetext{
${ }^{1}$ This figure is based on own calculations from the data.
} 
added in manufacturing shrinks. TFP growth in manufacturing will not, however, be affected if this reduction occurred due to reallocation of inputs to other sectors.

There are studies considering the TFP growth within manufacturing in other countries using stochastic frontier models. Generally, these studies use a time trend approach (see e.g., Kim and Han 2001; Gounder and Xayavong 2004; Kim and Shafi'i 2009). One exception is Zheng et al. (2008), who use both a time trend and additional time dummies for some years in order to capture external shocks.

A few, but not many, studies investigate impacts on productivity and efficiency during and after the financial crisis of 2008-2009. For instance, Kapelko et al. (2014) examine dynamic inefficiency of the Spanish constructing sector pre- and post-financial crisis. They found that the dynamic cost inefficiency is larger before the crisis. In addition, Kapelko and Oude Lansink (2015) study technical efficiency, and its determinants, for the construction sector in Spain using data envelopment analysis (DEA). Technical efficiency is shown to be significantly lower during the beginning of the crisis. TFP and labor productivity have been studied by Harris and Moffat (2016) in the UK. The significant decline post-2008 did not recover before 2012 . Therefore, they concluded that the loss in productivity is likely to be permanent rather than cyclical. Recently, Kapelko et al. (2017) investigated the impact on dynamic productivity growth in the Spanish food manufacturing industry using the Luenberger productivity indicator. Negative impacts on productivity were found. However, diverse effects are observed between different subindustries and firm-sizes. ${ }^{2}$

To the best of our knowledge, no study targets TFP change or the level of technical efficiency for manufacturing firms in Sweden during and after the financial crisis during 2008-2009. However, there are studies of the Swedish manufacturing sector. The earliest study is Carlsson (1972) who studies technical efficiency in Swedish production. Carlsson (1972) concludes the adjusted average efficiency index to be between 0.577-0.905, depending on the industry, using cross-sectional data from $1968 .^{3}$ Additionally, Kumbhakar and Heshmati (1996) as well as Oh et al.

\footnotetext{
2 A few studies can also be found that relate to the banking sector, e.g., Papagiannis (2014) and Das and Patra (2016). Furthermore, Aguiar et al. (2017) estimate a stochastic frontier for OECD countries, among other countries, concluding an annual TFP growth of $0.29 \%$ from 2001-2011. Efficiency and productivity during the Asian crisis is also investigated by Park and Weber (2006), who also elaborate on the issues with concluding technical regress.

${ }^{3}$ Carlsson (1972) provides a comprehensive theoretical part on competition which will not be described further here.
}

(2012) investigated TFP in Sweden. ${ }^{4}$ Both these studies uses panel data for the estimation. The years covered are 1964-1989 and 1992-2000. Using panel data and average translog production functions, Kumbhakar and Heshmati (1996) and Oh et al. (2012) determine the time effect by a trend and dummies, i.e., the general index (GI) model (Baltagi and Griffin 1988). Both Kumbhakar and Heshmati (1996) and Oh et al. (2012) estimate RTS and decompose TFP growth into TC and SC. ${ }^{5}$ TC is further separated into neutral, non-neutral and scale augmenting TC. ${ }^{6}$ Kumbhakar and Heshmati (1996) conclude a TFP growth of approximately $1.91 \%$, on average, for their preferred model. Further, a negative TFP change was shown for several years driven by negative TC. Similar results are found in Oh et al. (2012), i.e., TFP change is $1.9-2.0 \%$ in the preferred, most flexible, models. Both studies argue that the GI is advantageous when the pattern of TC is erratic, to capture the years with negative TC. However, we argue that it does not give an estimate of the technical change in its original interpretation, i.e., a development of the technology. The reason is that cyclical factors, to a large extent, are captured because inputs are not fully flexible. For example, employees can, generally, not be terminated directly, and capital in standard models is assumed to be fixed in the short run. More discussion on interpretation of TC is provided in the next section.

In summary, only two studies in Sweden investigate TFP in the manufacturing sector and one considers efficiency. Each of these analyzes data that are at least 16 years old. Furthermore, neither of them focuses on the financial crisis of 2008-2009 nor estimate a stochastic frontier model.

\section{Measuring productivity and efficiency}

There are a number of different ways to measure TFP used in the literature. These can be divided into non-parametric measures such as the Divisia index or the Malmquist index (Caves et al. 1982; Diewert 1976; Färe et al. 1994), parametric measures like average production functions (Solow 1957) and SFA (Aigner et al. 1977; Meeusen and van Den Broeck 1977). Non-parametric measures based on DEA (Charnes et al. 1978) have the limitation of interpreting all deviation from the frontier as inefficiency and being sensitive to outliers. Thus, a parametric approach is applied

\footnotetext{
$\overline{4}$ Productivity is also considered in a few other studies centering on bad outputs, energy efficiency and climate, e.g. Lundgren et al. (2015), Bostian et al. (2016), Färe et al. (2016), and Lundgren and Zhou (2017).

${ }^{5}$ Oh et al. (2012) reported an RTS of between 1.022-1.030 for manufacturing and 1.020-1.026 for service.

${ }^{6}$ As Oh et al. (2012) use a production function, there is no scale augmenting TC.
} 
where SFA is the standard point of departure when modeling technical efficiency (see e.g., Greene 2008; Kumbhakar et al. 2017, for overviews). This section briefly describes the development of measuring efficiency with focus on SFA. Thereafter, a comparative description of measuring TFP using SFA and average production functions, including a discussion of interpretations, is provided.

\subsection{Efficiency}

Usage of panel data in the scope of SFA started in the early 1980s by Pitt and Lee (1981) and Schmidt and Sickles (1984), among others. The standard model can be formulated as:

$y_{i t}=f\left(\mathbf{x}_{i t}, t ; \boldsymbol{\beta}\right) \exp \left(-u_{i t}\right)$,

where $y_{i t}$ is the output for each firm $i(i=1, \ldots, N)$ at time $t$ $(t=1, \ldots, T), \mathbf{x}_{i t}$ is the vector of inputs quantities, $t$ is the time trend and $\boldsymbol{\beta}$ is the corresponding coefficient to be estimated. Finally, technical inefficiency, referred to as $u_{i t}$, is non-negative. The SFA assumes that an idealized production frontier can be found where the one-sided deviation from the frontier is referred to as inefficiency. Throughout the development of new models in the SFA literature, a debate regarding identification and/or interpretation of the efficiency term has been present. In the early cases, inefficiency may change between producers, but not over time (see e.g., Pitt and Lee 1981; Kumbhakar 1987; Battese and Coelli 1988). The assumption of constant inefficiency is argued to be unrealistic when the number of time periods is large and the competition is high. Therefore, inefficiency can also be considered as time-varying (see e.g., Kumbhakar 1990, Lee and Schmidt 1993).

During the 1990s, the error term was separated into three parts. Kumbhakar and Heshmati (1995) developed a model that views the time-invariant effect as persistent inefficiency. However, the persistent part in these models does not account for the fact that the time-invariant effect is likely to be, partly, a result of firm-heterogeneity. Therefore, Greene (2005a, 2005b) decomposes the error into firmspecific time-varying inefficiency, firm-specific random- or fixed effects, to capture latent heterogeneity and random noise. The issue here is that any producer-specific and timeinvariant component is considered as unobserved heterogeneity. Thus, the differences between the different threecomponent models are related to interpretation. Consequently, both models have the drawback that firmheterogeneity and persistent inefficiency is not disentangled.

There has been renewed interest in efficiency modeling due to the methodological development, starting with Colombi et al. (2014), Tsionas and Kumbhakar (2014) and Kumbhakar et al. (2014) that simultaneously proposed separation of the disturbance into four components. Furthermore, Filippini and Greene (2016) proposed implementation of the model by a simulated maximum likelihood approach. These models separate persistent inefficiency from firm-heterogeneity and transient inefficiency from random noise. Persistent inefficiency is important, from a policy perspective, because it includes time-invariant effects of inputs such as management and other unobserved factors (Mundlak 1961). For further description of the development and comparisons of models, see e.g., Filippini and Greene (2016), Heshmati et al. (2018) or Kumbhakar et al. (2017). ${ }^{7}$

In the analysis, we have made the standard assumption regarding exogeneity of inputs. If the assumption does not hold, it might cause underestimation of the output elasticity of capital and firm-level technical efficiency according to e.g. Shee and Stefanou (2015). Methods to handle endogeneity when estimating an average production function are e.g. Olley and Pakes (1996) and Levinsohn and Petrin (2003) that attempts to identify unobserved productivity shocks by investments and intermediate inputs, respectively. These approaches were extended in Ackerberg et al. (2015) to handle the functional dependence. A few problems with the above mentioned methods are discussed by, for example, De Loecker (2011) and Van Beveren (2012). Above mentioned studies estimate average production functions and, for example, Shee and Stefanou (2015) note that it has to a large extent been ignored in SFA. Shee and Stefanou (2015) proposed an extension of the semiparametric approach suggested in Levinsohn and Petrin (2003) to the SFA case. Another example that attempt to handle endogeneity in SFA is Lai and Kumbhakar (2018).

\subsection{Total Factor Productivity}

TFP is often empirically measured by a production function which is identical to the stochastic frontier model without an inefficiency component, i.e., inefficiency is zero, written as equation 2 .

$y_{i t}=f\left(\mathbf{x}_{i t}, t ; \boldsymbol{\beta}\right)$.

Before elaborating on the potential interpretation issues, the time derivative of the translog production function is presented in equation 3 .

$\frac{\partial y_{i t}}{\partial \mathrm{t}}=\beta_{\mathrm{t}}+\beta_{\mathrm{tt}} t+\sum_{i}^{I} \boldsymbol{\beta}_{i t} \mathbf{x}_{\mathrm{i}}$

where both $\beta_{t}$ and $\beta_{t t}$ are equivalent for all firms. The expression in equation 3 is often claimed to be firm-specific. However the firm-specific part can be questioned because it

\footnotetext{
${ }^{7}$ Other studies also incorporate determinants of the different components of efficiency, e.g., Badunenko and Kumbhakar (2017) and Lai and Kumbhakar (2018).
} 
only differs depending on the level of inputs, as can be seen in equation 3 (Baltagi et al. 1995). ${ }^{8}$ Studies that investigate TFP using an average function generally interpret equation 3 as $\mathrm{TC}_{i t}$, i.e., shift of the production function. ${ }^{9}$ In SFA, most attention targets identification and/or interpretation of efficiency (see e.g., Kumbhakar et al. 2017 for an overview) meaning that less effort is given $\mathrm{TC}_{i t}$. However, for example, Kumbhakar (2000) show that $\mathrm{TC}_{i t}$ from the average production function can be separated into frontier shift $\left(\mathrm{TC}_{i t}\right)$ and technical efficiency change $\left(\mathrm{TEC}_{i t}\right)$ by usage of SFA. ${ }^{10}$ If $\mathrm{TC}_{i t}$ and $\mathrm{TEC}_{i t}$ are considered separately, the straightforward economic interpretation is often argued to be the main advantage, i.e., shift of the frontier and catching-up to best practice (see e.g., Pires and Garcia 2012). Regardless of the straightforward interpretation, identification of the separate components is crucial for usefulness.

Identification should require different estimates of $\mathrm{TC}_{i t}$ depending on whether a stochastic frontier model or an average model has been estimated (given that $\mathrm{TEC}_{i t}$ is different from zero). However, these models only differ in their distribution assumption of the disturbance, which is not likely to affect the estimated coefficients in the production function but only the intercept (Aigner et al. 1977). In SFA, each firm obtains an estimate of $\mathrm{TC}_{i t}$ regardless of whether they operate on the frontier. The average of these estimates is then considered as the $\mathrm{TC}_{i t}$ and, commonly, interpreted as a frontier shift. ${ }^{11}$ Conclusively, the $\mathrm{TC}_{i t}$ in SFA will equalize the $\mathrm{TC}_{i t}$ in the average function if the coefficients do not differ. In this aspect, Kumbhakar and Lien (2017) state that no differences in $\mathrm{TC}_{i t}$ between their model 1 (Kumbhakar and Heshmati 1995) and model 2 (Greene 2005a, 2005b) is expected because their deterministic parts are equivalent. ${ }^{12}$ However, despite the equivalence of the deterministic parts-the implications of the different time derivatives are different given the previous argument that SFA interprets it as frontier shift. Little attention to these interpretation issues can be found in the

\footnotetext{
8 There are other extensions regarding firm-specific components that provide more reliable estimates, e.g., Sun, Kumbhakar and Tveterås (2015). Unreliable estimates on the firm-level are particularly problematic when a second-stage regression on determinants is performed, which, for example, Baltagi et al. (1995) and Wang and Schmidt (2002) previously addressed.

9 To obtain the estimate of TFP change, a component of SC is also calculated and added together with $T C_{i t}$, as shown in the methodology.

10 A similar decomposition is also performed by Bauer (1990).

11 This is different from Nishimizu and Page (1982), who estimate TC based on a subset of frontier firms. Further, it should be noted that Aigner et al. (1977) did not have the concern of this separation because they use a cross-section.

12 The Kumbhakar and Heshmati (1995) model is a multistep procedure with an average function in the first stage, and Greene $(2005 a, 2005 b)$ is a frontier model, i.e., true random effect and true fixed effect.
}

literature. Based on these arguments, a reliable estimate of frontier shift can be difficult to find using these models, given that the interpretation is development of the frontier firms. An additional issue relates to disentangle $\mathrm{TC}_{i t}$ and $\mathrm{TEC}_{i t}$. Problems occur both based on previous arguments on potential issues of identifying the frontier shift as well as the fact that the components have simultaneous time variation (see e.g., Greene 2005b). ${ }^{13}$ The contradictory interpretation is addressed by, for example, Lovell (1996).

This section can, apart from the brief overview, be summarized in three points. First, it provides motives to raise the question of how $\mathrm{TC}_{i t}$ should be interpreted in SFA, i.e., should it be understood as a frontier shift? Second, a clearcut separation between $\mathrm{TEC}_{i t}$ and $\mathrm{TC}_{i t}$ should be performed with care in SFA. The reason is that identification issues occur, from an econometric point of view, in reliably assigning the simultaneously changing time components to either $\mathrm{TC}_{i t}$ or $\mathrm{TEC}_{i t}$. Third, applied researchers should, if no separation is performed, be clear in how $\mathrm{TC}_{i t}$ is interpreted, i.e., the estimate of $\mathrm{TC}$ may include what, for example, Kumbhakar (2000) address as both $\mathrm{TC}_{i t}$ and $\mathrm{TEC}_{i t}$.

\section{Methodology}

This paper adopts the four-component SFM because it improves previous models in several ways. First, previous models in the manufacturing sector are likely to fail in identifying factors with persistent effects on efficiency (see e.g., Heshmati et al. 2018). Second, a common assumption is that inefficiency is independent over time. More reasonable is to assume that one component of efficiency can be removed and another is fixed. Third, identification of these components is important from a policy perspective, since different interventions are necessary depending on what is to be targeted (see e.g., Kumbhakar and Lien 2017).

Each of the four proposed four-component models identifies the transient and persistent efficiency consistently, but in different ways, i.e. in one or several steps. This paper applies the Kumbhakar et al. (2014) multistep procedure because it is straightforward to implement and verification is possible in each step. ${ }^{14} \mathrm{~A}$ translog specification is used to

\footnotetext{
13 This is in contrast to the long debate in the literature regarding different components of efficiency previously briefly described.

${ }^{14}$ The usual argument against the Kumbhakar et al. (2014) alternative is that it is not as efficient as the single-stage procedures. However, this is not crucial when the number of observations is large. Furthermore, the maximum likelihood model suggested by Colombi et al. (2014) is "computationally prohibitive when $\mathrm{T}$ is large" (Tsionas and Kumbhakar, 2014, p. 115). The Filippini and Greene (2016) version has also been estimated; however, numerical issues occurred in parts of the data set. More detailed discussions regarding the different estimation procedures are performed in, for example, Filippini and Greene (2016), Heshmati et al. (2018) and Filippini et al. (2018).
} 
Table 1 Descriptive statistics of the used variables

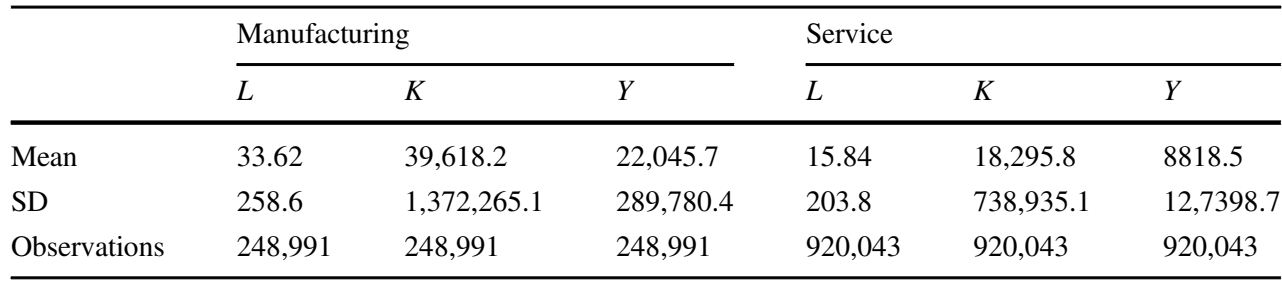

allow for different RTS (Christensen et al. 1973). The model is specified in equation 4.

$y_{i t}=a_{0}+f\left(\mathbf{x}_{i t}, t ; \boldsymbol{\beta}\right)+\mu_{i}-\eta_{i}+v_{i t}-u_{i t}$.

The first disturbance component $\left(\mu_{i}\right)$ captures firms' latent heterogeneity (Greene 2005a, 2005b) which is disentangled to identify the second component, persistent inefficiency (Kumbhakar and Heshmati 1995). Random shocks are represented by the third component $\left(v_{i t}\right)$ and, finally, the last term is the transient $\left(u_{i t}\right)$ inefficiency. The product of the persistent and transient efficiency is referred to as overall efficiency as suggested by Kumbhakar et al. (2014). A short description of how the different components are identified will now be provided.

To apply the Kumbhakar et al. (2014) multistep procedure, equation 4 is rewritten to panel data type as equation 5:

$y_{i t}=\alpha_{0}^{*}+f\left(\mathbf{x}_{i t} ; \boldsymbol{\beta} ; t\right)+\alpha_{i}+\varepsilon_{i t}$

where one can define $\alpha_{0}^{*}=a_{0}-E\left(\eta_{i}\right)-E\left(u_{i t}\right) ; \alpha_{i}=\mu_{i}-\eta_{i}$ $+E\left(\eta_{i}\right)$; and $\varepsilon_{i t}=v_{i t}-u_{i t}+E_{i t}\left(u_{i t}\right)$ for estimation purposes. Using this specification, $\alpha_{i}$ and $\varepsilon_{i t}$ have zero mean and constant variance. The multistep procedure is applied in three steps. First, equation 5 is a standard panel data model and is estimated by random effects to obtain $\widehat{\boldsymbol{\beta}} \cdot{ }^{15}$ Additionally, predicted values of the time-invariant component, $\alpha_{i}$, and the time-varying component, $\varepsilon_{i t}$, are acquired. Second, identification of the transient efficiency requires the assumptions that $v_{i t}$ is i.i.d. $N\left(0, \sigma_{v}^{2}\right)$ and $u_{i t}$ is i.i.d. $N^{+}\left(0, \sigma_{u}^{2}\right)$. Using these assumptions, the transient inefficiency is identified by standard SFA through the Jondrow et al. (1982) procedure. Transient efficiency is then calculated as $\exp \left(-u_{i t}\right)$. The third step is a repetition of the second using the time-invariant components and assuming that $\mu_{i}$ is i.i.d. $N\left(0, \sigma_{\mu}^{2}\right)$ and $\eta_{i}$ is i.i.d. $N^{+}\left(0, \sigma_{\eta}^{2}\right)$.

Furthermore, TC is estimated as equation 3. Therefore, TC is interpreted as a movement of the average production function, i.e., this is not equivalent to a shift of the frontier

\footnotetext{
15 A fixed effect model is also possible to use. However, the estimates of RTS becomes unreliable, e.g., 0.845 for manufacturing using that so the random effect is chosen, therefore it is more relevant to rely on economic intuition, i.e. the RTS should be close to CRS. Additionally, a random effect is motivated by the fact that we have heterogeneity within the sectors, manufacturing and service, used for the analysis. For further discussion, see e.g. Bell and Jones (2015).
}

meaning that a separation between TC and TEC cannot be made. RTS is calculated as the sum of the input elasticities, i.e., $\sum_{i} \epsilon_{i}$, where $\epsilon_{i}=\partial \mathrm{f} / \partial \ln \mathbf{x} i$. Based on RTS, the SC is calculated as $(\mathrm{RTS}-1) \sum_{i} \lambda_{i} \dot{x}_{i}$, where $\lambda_{i}=\epsilon_{i} / \mathrm{RTS}$ and $\dot{x}_{i}$ represents the change in inputs.

\section{Data}

An unbalanced firm-level panel data set that covers all Swedish firms within the manufacturing and service industries during the period 1997-2013 is obtained from Statistics Sweden (SCB). ${ }^{16}$ This period is of particular interest due to the global financial crisis. The reason is the investigation possibilities of how an export-dependent sector (in comparison to a sector likely to export less) in Sweden, such as manufacturing (service), performed before, during and after the crisis. Included firm characteristics are: capital assets $(K)$, number of full-time employees $(L)$, and value added $(Y) . K$ and $Y$ are in 1997 prices measured in thousands of SEK. Descriptive statistics is reported in Table 1.

The descriptive statistics in Table 1 is reported after elimination of outliers. No universally accepted method for outlier detection is present in the literature. However, we follow the most recent study on TFP for Swedish manufacturing firms and identify an observation as an outlier if the value added the present year changes more than $80 \%$ in comparison to the previous year (Oh et al. 2012). ${ }^{17}$ Furthermore, the included variables are incorporated in the production function as logarithms. Observations where the logarithm becomes missing or zero are eliminated because their marginal products do not make economic sense. After this exclusion, the data consists of 30,144 unique firms over time that becomes 248,991 observations within different sub-sectors of manufacturing. The sector classification of Statistics Sweden is used to categorize the manufacturing sector into 11 sub-sectors. For the service sector, there is not a specific main category provided by Statistics Sweden.

\footnotetext{
16 The manufacturing sector consists of the two-digit SNI2002 from 15 to 37, and the service sector is defined SNI2002 50-52, 60-64 and 71-74. All sector codes are transformed to the SNI2002 using the key provided by Statistics Sweden.

${ }^{17}$ We have also used other thresholds, for example $60 \%$, with consistent results.
} 
However, three sub-sectors are included as service: (1) wholesale and retail trade, (2) transport and storage, and (3) renting and business activities. These are aggregated to 920,043 observations, and the descriptive statistics, after the same elimination as for manufacturing, is presented in Table $1 .^{18}$

\section{Results}

The first part of the results considers efficiency and its different components, which provide an estimate of performance in relative terms. Second, RTS, TC and SC are presented, where the two latter components sum to TFP change. ${ }^{19}$

\subsection{Technical efficiency}

In this section, overall, persistent and transient efficiency will be analyzed. At first, these components are reported as averages over time in Fig. 2.

In Fig. 2, the blue lines show the different components of efficiency for the manufacturing and the red lines show the service sector. The persistent part for manufacturing (service) is $0.796(0.754)$ and the transient part is $0.787(0.762)$, which indicates improvement potentials. ${ }^{20}$ An interpretation of this is that manufacturing has its largest share of inefficiency in the transient component, while the service sector has the largest inefficiency in the persistent part. However, the differences are fairly small. A potential outcome on persistent efficiency during and after a financial crisis would be an improvement, since firms with a low persistent efficiency are likely to be driven out of the market. In our case, this does not occur, meaning that the firms with low persistent efficiency remain in the market.

The transient part of efficiency drops during 2000-2003 and 2007-2009, with larger changes for manufacturing in comparison to the service sector. ${ }^{21}$ Corresponding to the period after the financial crisis, i.e., after 2009, both sectors increase their transient efficiency to levels equivalent to that

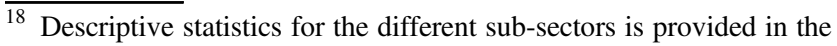
appendix.

19 As pointed out in Section 3, endogeneity of inputs could bias the results. However, our results, before the financial crisis, are in line with previous studies on Swedish data and a larger elasticity of capital would generate a larger RTS, which is economically non-intuitive on a competitive market. Therefore, it seemed reasonable to maintain the assumption.

${ }^{20}$ Kernel distributions of the different components of efficiency are shown for manufacturing (service) in Fig. 3 (A2) in the appendix. Further, a table showing the exact efficiency scores to construct Fig. 2 is provided in the appendix.

21 The same pattern is shown if time is represented by dummy variables for manufacturing, but no differences in efficiency can be observed for the service sector.
}

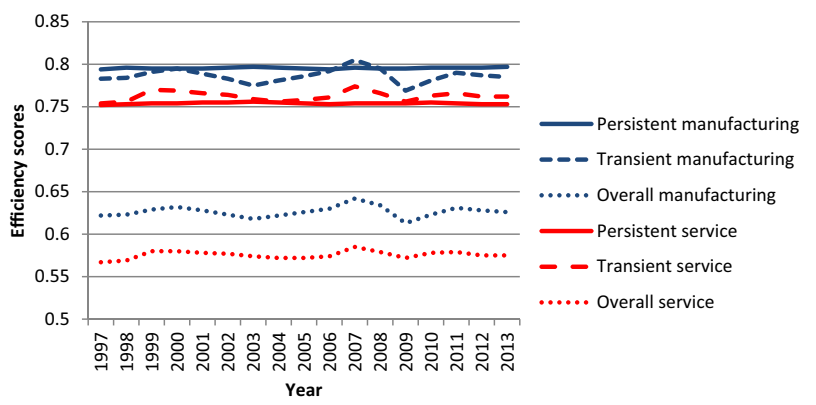

Fig. 2 The different components of efficiency over time for manufacturing and service

as before the decline-however, the changes are small for the service sector. Subsequently, transient efficiency does not show any considerable changes over time with the exception of the erratic change during the crisis. Diverse effects of the financial crisis could be observed on efficiency in the previous literature for other sectors and countries. Consistent with our results, for example, is a lower efficiency in the beginning of the crisis found by Kapelko and Oude Lansink (2015) for the Spanish construction sector. However, our study does not indicate any significant difference in efficiency for the whole post-crisis period, 2007-2013, compared to the previous period. Comparing the level of efficiency by sector, it can be observed that the manufacturing sector has higher efficiency, which is expected in order to the higher competition, internationally. Focusing on manufacturing (service) in relation to firm size, it can be observed that the transient efficiency is approximately the same, regardless of size. However, the persistent efficiency is $0.784(0.745)$ for the smallest firms, i.e., fewer than 10 employees, and $0.848(0.828)$ for firms with more than 300 employees. This is intuitive because large firms are more likely to compete in an international market. ${ }^{22}$ Heterogeneity can, therefore, be observed in size, which is consistent with Kapelko and Oude Lansink (2015). Differences may also be present between sub-sectors; Table 2 reports the efficiency scores separated on these.

Table 2 reports the components of efficiency separated on the different sub-sectors for the whole time period. ${ }^{23}$ Persistent efficiency differs from 0.703 for RENT to 0.842 within BASI. A low level of persistent efficiency should not be present in a competitive sector. The RENT sector is likely to consist of many local firms and the competition may be low on the local level. However, BASI, COKE and $\mathrm{MACH}$, with the highest persistent efficiency, are more

\footnotetext{
${ }^{22}$ The other size groups are 10-50, 50-100 and 100-300 employees and the persistent efficiency for manufacturing (service) are 0.824 (0.787), $0.821(0.803)$ and $0.828(0.811)$, respectively.

${ }^{23}$ Only small changes occur if this is performed by the time periods 1997-2007 and 2007-2013. A table of this separation is provided in the appendix.
} 
Table 2 Persistent, transient and overall efficiency by sub-sector

\begin{tabular}{llll}
\hline By industry for 1997-2013 & Persistent & Transient & Overall \\
\hline All manufacturing & 0.796 & 0.787 & 0.627 \\
Food products, beverages and tobacco & 0.775 & 0.798 & 0.619 \\
Textile and leather products & 0.747 & 0.768 & 0.575 \\
Wood and products of wood & 0.768 & 0.800 & 0.616 \\
Pulp, paper, paper products, publishing and printing & 0.771 & 0.777 & 0.600 \\
Coke, refined petroleum products, nuclear fuel, chemicals, & 0.838 & 0.777 & 0.651 \\
rubber and plastic products (COKE) & & & \\
Other non-metallic mineral products & 0.746 & 0.805 & 0.602 \\
Basic metals and fabricated metal products (BASI) & 0.842 & 0.804 & 0.678 \\
Machinery and equipment n.e.c. (MACH) & 0.835 & 0.788 & 0.659 \\
Electrical and optical equipment & 0.777 & 0.767 & 0.597 \\
Transport equipment & 0.760 & 0.787 & 0.599 \\
Manufacturing n.e.c. & 0.792 & 0.800 & 0.635 \\
All service firms & 0.754 & 0.762 & 0.576 \\
Wholesale and retail trade; repair of motor vehicles, & 0.775 & 0.767 & 0.596 \\
motorcycles and personal and household goods & & & 0.664 \\
Transport, storage and communication & 0.828 & 0.801 & 0.527 \\
Renting and business activities (RENT) & 0.703 & 0.747 &
\end{tabular}

n.e.c. not elsewhere classified likely to have a large share of firms that operate in an international market. Differences, however, can be observed between these sub-sectors regarding the transient component. A potential mechanism behind this is differences in handling volatility in demand, i.e., flexible inputs. Studying the capital labor ratio between these sub-sectors, it can be observed that BASI has the lowest amount of capital given the labor, which is a sign of higher flexibility given that capital is a fixed input. Overall, BASI is the sector with highest efficiency and RENT has the lowest overall efficiency. To summarize, heterogeneity could be observed between sub-sectors and size groups. Only small changes in the efficiency components could be observed over time, with the exception of the period of 2009, i.e., the global financial crisis.

\subsection{Technical change, scale change and total factor productivity}

TC, SC and TFP are reported over time for the manufacturing and service sector in Table 3.

In Table 3, the TC, SC and TFP are reported for the manufacturing (on the left) and service sector on the right. On average, the RTS is 1.025 and 0.989 for manufacturing and service, respectively. ${ }^{24}$ It can be observed that the effect of changes in SC is approximately zero for manufacturing and slightly negative for the service sector. The contributor

\footnotetext{
${ }^{24}$ The input elasticities and RTS for the manufacturing and service sectors are reported in Table 5 in the appendix.
}

Table 3 TFP and its components using a single time trend

\begin{tabular}{|c|c|c|c|c|c|c|}
\hline \multirow[t]{2}{*}{ By year } & \multicolumn{3}{|c|}{ Manufacturing } & \multicolumn{3}{|l|}{ Service } \\
\hline & $\mathrm{TC}$ & $\mathrm{SC}$ & TFP & $\mathrm{TC}$ & $\mathrm{SC}$ & TFP \\
\hline 1997 & - & - & - & - & - & - \\
\hline 1998 & $1.74 \%$ & $0.05 \%$ & $1.79 \%$ & $2.06 \%$ & $-0.33 \%$ & $1.74 \%$ \\
\hline 1999 & $1.64 \%$ & $0.01 \%$ & $1.65 \%$ & $1.95 \%$ & $-0.21 \%$ & $1.74 \%$ \\
\hline 2000 & $1.55 \%$ & $0.03 \%$ & $1.58 \%$ & $1.85 \%$ & $-0.34 \%$ & $1.51 \%$ \\
\hline 2001 & $1.47 \%$ & $0.03 \%$ & $1.50 \%$ & $1.77 \%$ & $-0.24 \%$ & $1.53 \%$ \\
\hline 2002 & $1.40 \%$ & $0.01 \%$ & $1.41 \%$ & $1.70 \%$ & $-0.18 \%$ & $1.52 \%$ \\
\hline 2003 & $1.33 \%$ & $0.00 \%$ & $1.33 \%$ & $1.62 \%$ & $-0.12 \%$ & $1.50 \%$ \\
\hline 2004 & $1.26 \%$ & $0.01 \%$ & $1.27 \%$ & $1.52 \%$ & $-0.12 \%$ & $1.40 \%$ \\
\hline 2005 & $1.19 \%$ & $0.04 \%$ & $1.23 \%$ & $1.45 \%$ & $-0.13 \%$ & $1.32 \%$ \\
\hline 2006 & $1.12 \%$ & $0.06 \%$ & $1.18 \%$ & $1.37 \%$ & $-0.14 \%$ & $1.23 \%$ \\
\hline 2007 & $1.06 \%$ & $0.09 \%$ & $1.15 \%$ & $1.31 \%$ & $-0.13 \%$ & $1.18 \%$ \\
\hline 2008 & $1.00 \%$ & $0.10 \%$ & $1.10 \%$ & $1.24 \%$ & $-0.12 \%$ & $1.12 \%$ \\
\hline 2009 & $0.90 \%$ & $-0.09 \%$ & $0.82 \%$ & $1.15 \%$ & $-0.06 \%$ & $1.08 \%$ \\
\hline 2010 & $0.83 \%$ & $-0.03 \%$ & $0.80 \%$ & $1.07 \%$ & $-0.07 \%$ & $1.00 \%$ \\
\hline 2011 & $0.77 \%$ & $0.10 \%$ & $0.87 \%$ & $1.00 \%$ & $-0.05 \%$ & $0.94 \%$ \\
\hline 2012 & $0.70 \%$ & $0.07 \%$ & $0.77 \%$ & $0.91 \%$ & $-0.03 \%$ & $0.88 \%$ \\
\hline 2013 & $0.61 \%$ & $0.00 \%$ & $0.61 \%$ & $0.82 \%$ & $-0.03 \%$ & $0.79 \%$ \\
\hline Mean & $1.14 \%$ & $0.03 \%$ & $1.17 \%$ & $1.36 \%$ & $-0.13 \%$ & $1.24 \%$ \\
\hline
\end{tabular}

to TFP growth is, instead, TC, which indicates an annual progress of between 0.61 and $1.74 \%$ for manufacturing and between 2.06 and $0.82 \%$ for service. These changes are smooth over time by construction and the technical progress is interpreted as a shift upwards of the average production 
Table 4 TFP separated on time periods and sub-sectors
$1997-2007 \quad 2007-2013 \quad 1997-2013$

\begin{tabular}{llll}
\hline Manufacturing & & & \\
All manufacturing & $1.98 \%$ & $0.44 \%$ & $1.17 \%$ \\
Food products, beverages and tobacco & $1.47 \%$ & $2.21 \%$ & $1.35 \%$ \\
Textile and leather products & $1.22 \%$ & $-0.21 \%$ & $0.65 \%$ \\
Wood and products of wood & $2.67 \%$ & $-0.74 \%$ & $1.25 \%$ \\
Pulp, paper, paper products, publishing and printing & $1.29 \%$ & $-0.14 \%$ & $0.84 \%$ \\
Coke, refined petroleum products, nuclear fuel, chemicals, & $2.02 \%$ & $1.64 \%$ & $1.40 \%$ \\
rubber and plastic products & & & \\
Other non-metallic mineral products & $2.48 \%$ & $0.44 \%$ & $1.45 \%$ \\
Basic metals and fabricated metal products & $2.07 \%$ & $0.41 \%$ & $1.14 \%$ \\
Machinery and equipment n.e.c. & $1.99 \%$ & $0.48 \%$ & $1.26 \%$ \\
Electrical and optical equipment & $2.49 \%$ & $0.24 \%$ & $1.64 \%$ \\
Transport equipment & $1.99 \%$ & $1.28 \%$ & $1.07 \%$ \\
Manufacturing n.e.c. & $1.74 \%$ & $0.36 \%$ & $1.00 \%$ \\
Service & & & \\
All service firms & $1.80 \%$ & $0.54 \%$ & $1.24 \%$ \\
Wholesale and retail trade; repair of motor vehicles, motorcycles & $1.99 \%$ & $0.67 \%$ & $1.34 \%$ \\
and personal and household goods & & & \\
Transport, storage and communication & $1.41 \%$ & $0.28 \%$ & $0.69 \%$ \\
Renting and business activities & $1.62 \%$ & $0.48 \%$ & $1.29 \%$ \\
\hline
\end{tabular}

n.e.c. not elsewhere classified function. This occurs if: (1) inefficient firms catch-up or (2) the frontier firms perform better. These effects are not directly disentangled in this paper, i.e., TC is not interpreted separated from TEC based on the arguments elaborated in Section 3. Since the prior results are smooth over time, we would like to pinpoint the periods before and after the financial crisis by estimating TFP on the sub-sector level separated into these periods, i.e., 1997-2007 and 2007-2013. ${ }^{25}$ These results are reported in Table 4.

In Table 4, TFP is reported over the whole studied periods, 1997-2013, and separated before and after the crisis, i.e. 1997-2007 and 2007-2013, respectively. From the right column in Table 4, it can be observed that the average TFP growth was 1.17 and $1.24 \%$ for manufacturing and service, respectively. This is mainly driven by $\mathrm{TC}$, which is reported separately in the appendix. By separating the pre- and postfinancial crisis periods it can be observed that manufacturing showed a TFP growth of $1.98 \%$, and service $1.80 \%$, during the pre-crisis period. In comparison, both industries indicate a substantially lower annual TFP growth from 2007-2013, i.e., 0.39 and $0.54 \%$ for manufacturing and service, respectively. In comparison to the previous literature on Swedish data, TFP change during the pre-crisis

\footnotetext{
$\overline{25}$ The single time trend does not incorporate technology shifters analyzed by e.g., Heshmati and Kumbhakar (2014).
}

period is in the same range, but the post-period is lower. Furthermore, our findings points in the same direction as the result in Harris and Moffat (2016), i.e. TFP has not recovered after the financial crisis. By performing the same separation on the sub-sectors, this pattern is observed in all sub-sectors with a few exceptions, which are consistent with Kapelko et al. (2017). ${ }^{26}$ It should, however, be noted that we cannot identify whether this is a causal effect of the financial crisis.

The majority of the sectors indicate a pattern of lower TFP change after 2007. The exception is food, beverages and tobacco and a potential mechanism behind that is that these goods are less likely to be affected by cyclical changes than other products. Furthermore, a few sub-sectors indicate a negative TFP change driven by negative TC, which has an economically counterintuitive interpretation. ${ }^{27}$ At least two potential scenarios can explain the mechanism that will emerge as a technical regress in the model: (1) absence of reinvestment in capital, which made the capital stock less productive and (2) a decline in demand that made the firms unwilling to produce more outputs, while the inputs were not adjusted accordingly. The latter should, however, only affect firms in the short-run, and as we use a time trend over

\footnotetext{
$\overline{26}$ The reason that the TFP for the whole period is not between the single periods for all sub-sectors is that the first year in each sub-period is not accounted for in the measure of TC and SC (see Kumbhakar et al. 2015, p. 291-292).

27 A similar table of TC is provided in Table 8 the appendix.
} 
several years to represent TC, the cyclical changes should be smoothed. Recapping from the previous discussion, the interpretation is, in our case, not necessarily a movement inward of the production frontier, since TEC and TC are, partly, collapsed. Erratic changes will be captured in the transient efficiency component previously analyzed and continuous efficiency changes, i.e., poor performing firms that do worse over time are captured in TC. Consequently, whether or not the lower TFP growth in the latter period is driven by weaker progress of frontier firms, or less improvement of inefficient firms in relation to the frontier, cannot be directly disentangled. However, the decline in transient efficiency during 2009 also holds if time is indicated by dummies for the manufacturing sector. Therefore, it is possible to state that the lower TC during the postperiod is, at least, partly driven by inefficient firms within the manufacturing sector. ${ }^{28}$

This study adopted a time trend to smooth the changes and separated the time period into 1997-2007 and 2007-2013 due to the suspicion of different patterns with the source in the financial crisis. However, previous research on TFP within manufacturing on Swedish data, among others, argues that the time trend performs poorly when changes are erratic. Thus, a short year-by-year analysis, i.e., time dummies, is also performed, represented by Fig. 5 in the appendix. These results indicate that the manufacturing caught up to its previous level in 2011-but not to its previous trend. ${ }^{29}$ In contrast, the service sector is, visually, at the same trend as previously, which is in line with was shown for aggregated value added in Fig. 1.

\section{Conclusion and policy recommendations}

This study investigated TFP and its decomposed factors for the Swedish manufacturing and service industries between 1997 and 2013, targeting the financial crisis, using firm level panel data from Statistics Sweden. A four-component stochastic frontier is carried out, which permits decomposition of the disturbance into firm-heterogeneity, persistent efficiency, transient efficiency and random noise. Moreover, RTS, TC and SC are investigated, where the two latter sum to TFP change. Additionally, a discussion regarding interpretation in the scope of SFA is performed, where a question regarding how TC should be understood is raised.

The results show that there are potentials to improve efficiency where the persistent efficiency is 0.796 for manufacturing and 0.754 for the service sector. Further, the

\footnotetext{
$\overline{28}$ This pattern is not observed for the service sector.

29 This is, however, not TC in its original interpretation, since these changes are clearly a result of cyclical factors.
}

transient efficiency is 0.787 and 0.762 for manufacturing and service, respectively. Over time, each of the components is fairly stable, with the exception of the transient component within the manufacturing sector during the financial crisis. Heterogeneity can be observed on size and sub-sectors, i.e., large firms and firms within sub-sectors that are more likely to compete in an international market have higher persistent efficiency. TFP growth is observed to differ substantially between the two periods, 1997-2007 and 2007-2013. During the pre-crisis period, TFP growth is 1.98 and $1.80 \%$ for manufacturing and service, respectively. This can be compared to the post-crisis period TFP growth of $0.44 \%$ for manufacturing and $0.54 \%$ for service, driven by a lower of TC. This pattern is fairly similar for all subsectors, with a few exceptions. Lower TC can have its source in either slower shift of frontier firms, less catchingup of inefficient firms or a mix of these. This study does not make a distinction between TC and TEC. However, a decline in transient efficiency during 2009 could be observed for manufacturing also when time was represented by dummy variables. In comparison to the lower TC in our main model, this means that the slow-down, at least to some extent, is driven by inefficient firms in the manufacturing sector.

Our results indicate that TFP change is substantially lower during and after the financial crisis, driven by lower TC. This means that TC is not back on its original trend of around $2 \%$ annually, observed for our pre-crisis period as well as by Kumbhakar and Heshmati (1996) and Oh et al. (2012). Since TC is concluded to be the largest share of TFP change in this study, and previous studies in Sweden, it is an important source to drive TFP change and, thus, economic growth. Therefore, policy makers should target interventions that enhance technology, e.g., increase the attractiveness to invest and be innovative. However, TC can also be held back when firms that perform poorly stay in the market. Therefore, potential interventions should be targeted to firms with potential to drive the technology and not be given to low-productivity firms that would otherwise close down. Furthermore, the persistent efficiency can, for example, be related to regulations or differences in human capital that does not change over time. In contrast, the transient part of efficiency is handled by "carrots and sticks" (Kumbhakar and Lien 2017). Particularly, it is the persistent part that is necessary to identify, since firms with a low level of persistent efficiency are not sustainable in a highly competitive market. One common source of the persistent part is regulation meaning that all firms in the sector will suffer. However, further research is necessary to determine the particular sources that can drive persistent, transient efficiency and TFP growth in the right direction. Finally, since the aim of this paper is not to state an appropriate interpretation of TC in the scope of SFA, more emphasis 
regarding this in relation to TEC should be taken in the future. In particular, a study can be made where a model attempt to separate between TC and TEC to be compared with another where no distinction is made as well as a more detailed analysis whether the components can be separated accurately.

Acknowledgements We wish to thank those persons who contributed their insightful comments during the seminars at Queensland University of Technology (QUT), the SWEGPEC Annual Workshop in Linköping, 2016, Linnaeus University, and the 12th APPC conference in Seoul, 2018. Finally, we would like to thank the anonymous referees for helpful comments and suggestions. Open access funding provided by Linnaeus University.

\section{Compliance with ethical standards}

Conflict of interest The authors declare that they have no conflict of interest.

Publisher's note Springer Nature remains neutral with regard to jurisdictional claims in published maps and institutional affiliations.

Open Access This article is distributed under the terms of the Creative Commons Attribution 4.0 International License (http://crea tivecommons.org/licenses/by/4.0/), which permits unrestricted use, distribution, and reproduction in any medium, provided you give appropriate credit to the original author(s) and the source, provide a link to the Creative Commons license, and indicate if changes were made.

\section{Appendix}

Tables 5-9, Figs. 3-5

Table 5 Input elasticities and returns to scale

\begin{tabular}{llllllll}
\hline & \multicolumn{2}{l}{ Manufacturing } & & Service & \\
\cline { 2 - 3 } By year & Capital & Labor & RTS & & Capital & Labor & RTS \\
\hline 1997 & 0.122 & 0.862 & 0.984 & 0.096 & 0.851 & 0.947 \\
1998 & 0.120 & 0.866 & 0.986 & 0.093 & 0.858 & 0.951 \\
1999 & 0.118 & 0.868 & 0.986 & 0.092 & 0.863 & 0.956 \\
2000 & 0.117 & 0.872 & 0.989 & 0.091 & 0.869 & 0.960 \\
2001 & 0.113 & 0.877 & 0.990 & & 0.088 & 0.877 & 0.964 \\
2002 & 0.110 & 0.882 & 0.992 & 0.085 & 0.885 & 0.969 \\
2003 & 0.107 & 0.887 & 0.994 & 0.082 & 0.892 & 0.974 \\
2004 & 0.103 & 0.893 & 0.996 & 0.080 & 0.900 & 0.979 \\
2005 & 0.090 & 0.100 & 1.000 & 0.077 & 0.908 & 0.984 \\
2006 & 0.096 & 0.906 & 1.002 & 0.074 & 0.916 & 0.989 \\
2007 & 0.092 & 0.915 & 1.007 & 0.070 & 0.924 & 0.994 \\
2008 & 0.087 & 0.924 & 1.011 & 0.067 & 0.932 & 0.999 \\
2009 & 0.085 & 0.926 & 1.011 & 0.064 & 0.939 & 1.004 \\
2010 & 0.082 & 0.933 & 1.015 & 0.062 & 0.947 & 1.008 \\
2011 & 0.078 & 0.942 & 1.020 & 0.059 & 0.954 & 1.013 \\
2012 & 0.075 & 0.948 & 1.023 & 0.057 & 0.961 & 1.018 \\
2013 & 0.072 & 0.953 & 1.025 & 0.055 & 0.967 & 1.022 \\
\hline
\end{tabular}

Table 6 Persistent, transient and overall efficiency separated on sub-sectors and time-periods

\begin{tabular}{|c|c|c|c|c|c|c|}
\hline \multirow[t]{2}{*}{ By industry } & \multicolumn{3}{|c|}{ 1997-2007 } & \multicolumn{3}{|l|}{ 2007-2013 } \\
\hline & Persistent & Transient & Overall & Persistent & Transient & Overall \\
\hline All manufacturing & 0.795 & 0.788 & 0.627 & 0.796 & 0.788 & 0.628 \\
\hline Food products, beverages and tobacco & 0.779 & 0.800 & 0.624 & 0.769 & 0.797 & 0.614 \\
\hline Textile and leather products & 0.744 & 0.768 & 0.572 & 0.752 & 0.770 & 0.582 \\
\hline Wood and wood products & 0.768 & 0.801 & 0.616 & 0.768 & 0.801 & 0.617 \\
\hline $\begin{array}{l}\text { Pulp, paper, paper products, publishing and } \\
\text { printing }\end{array}$ & 0.770 & 0.777 & 0.599 & 0.772 & 0.780 & 0.604 \\
\hline $\begin{array}{l}\text { Coke, refined petroleum products, } \\
\text { chemicals, rubber and plastic products }\end{array}$ & 0.837 & 0.779 & 0.652 & 0.839 & 0.777 & 0.653 \\
\hline Non-metallic mineral products & 0.748 & 0.806 & 0.603 & 0.745 & 0.807 & 0.603 \\
\hline Basic metals and fabricated metal products & 0.841 & 0.806 & 0.678 & 0.843 & 0.806 & 0.680 \\
\hline Machinery and equipment n.e.c. & 0.835 & 0.789 & 0.659 & 0.836 & 0.791 & 0.662 \\
\hline Electrical and optical equipment & 0.775 & 0.768 & 0.596 & 0.778 & 0.769 & 0.600 \\
\hline Transport equipment & 0.760 & 0.789 & 0.601 & 0.759 & 0.786 & 0.598 \\
\hline Manufacturing n.e.c. & 0.788 & 0.800 & 0.632 & 0.796 & 0.801 & 0.639 \\
\hline All service firms & 0.754 & 0.763 & 0.576 & 0.754 & 0.764 & 0.578 \\
\hline $\begin{array}{l}\text { Wholesale and retail trade; repair of motor } \\
\text { vehicles, motorcycles and personal and } \\
\text { household goods }\end{array}$ & 0.776 & 0.768 & 0.596 & 0.774 & 0.768 & 0.596 \\
\hline Transport, storage and communication & 0.828 & 0.802 & 0.665 & 0.827 & 0.801 & 0.664 \\
\hline Renting and business activities & 0.702 & 0.746 & 0.525 & 0.704 & 0.750 & 0.531 \\
\hline
\end{tabular}

n.e.c. not elsewhere classified 
Table 7 Persistent, transient and overall efficiency by year

\begin{tabular}{|c|c|c|c|c|c|c|}
\hline \multirow[t]{2}{*}{ Year } & \multicolumn{3}{|c|}{ Manufacturing } & \multicolumn{3}{|l|}{ Service } \\
\hline & Persistent & Transient & Overall & Persistent & Transient & Overall \\
\hline 1997 & 0.794 & 0.783 & 0.622 & 0.752 & 0.754 & 0.567 \\
\hline 1998 & 0.796 & 0.784 & 0.623 & 0.753 & 0.756 & 0.569 \\
\hline 1999 & 0.795 & 0.791 & 0.629 & 0.754 & 0.77 & 0.58 \\
\hline 2000 & 0.795 & 0.795 & 0.632 & 0.754 & 0.769 & 0.58 \\
\hline 2001 & 0.795 & 0.789 & 0.628 & 0.755 & 0.766 & 0.578 \\
\hline 2002 & 0.796 & 0.783 & 0.623 & 0.755 & 0.764 & 0.577 \\
\hline 2003 & 0.797 & 0.775 & 0.618 & 0.756 & 0.759 & 0.574 \\
\hline 2004 & 0.796 & 0.781 & 0.622 & 0.755 & 0.756 & 0.572 \\
\hline 2005 & 0.795 & 0.786 & 0.626 & 0.754 & 0.758 & 0.572 \\
\hline 2006 & 0.794 & 0.792 & 0.63 & 0.753 & 0.761 & 0.574 \\
\hline 2007 & 0.796 & 0.805 & 0.642 & 0.754 & 0.774 & 0.585 \\
\hline 2008 & 0.795 & 0.795 & 0.634 & 0.754 & 0.766 & 0.579 \\
\hline 2009 & 0.795 & 0.769 & 0.613 & 0.754 & 0.756 & 0.572 \\
\hline 2010 & 0.796 & 0.781 & 0.623 & 0.755 & 0.763 & 0.578 \\
\hline 2011 & 0.796 & 0.79 & 0.631 & 0.754 & 0.766 & 0.579 \\
\hline 2012 & 0.796 & 0.787 & 0.628 & 0.753 & 0.762 & 0.575 \\
\hline 2013 & 0.797 & 0.785 & 0.626 & 0.753 & 0.762 & 0.575 \\
\hline
\end{tabular}

Table 8 Technical change separated on time periods and sub-sectors

\begin{tabular}{|c|c|c|c|}
\hline & $1997-2007$ & $2007-2013$ & $1997-2013$ \\
\hline \multicolumn{4}{|l|}{ By industry: manufacturing } \\
\hline All manufacturing firms & $1.93 \%$ & $0.39 \%$ & $1.14 \%$ \\
\hline Food products, beverages and tobacco & $1.45 \%$ & $2.13 \%$ & $1.37 \%$ \\
\hline Textile and leather products & $1.25 \%$ & $-0.26 \%$ & $0.68 \%$ \\
\hline Wood and wood products & $2.58 \%$ & $-0.72 \%$ & $1.19 \%$ \\
\hline $\begin{array}{l}\text { Pulp, paper, paper products, } \\
\text { publishing and printing }\end{array}$ & $1.22 \%$ & $-0.27 \%$ & $0.78 \%$ \\
\hline $\begin{array}{l}\text { Coke, refined petroleum products, } \\
\text { chemicals, rubber and plastic products }\end{array}$ & $2.00 \%$ & $1.56 \%$ & $1.40 \%$ \\
\hline Non-metallic mineral products & $2.37 \%$ & $-0.36 \%$ & $1.41 \%$ \\
\hline $\begin{array}{l}\text { Basic metals and fabricated metal } \\
\text { products }\end{array}$ & $2.06 \%$ & $-0.72 \%$ & $1.12 \%$ \\
\hline Machinery and equipment n.e.c. & $1.90 \%$ & $0.46 \%$ & $1.20 \%$ \\
\hline Electrical and optical equipment & $2.44 \%$ & $0.21 \%$ & $1.61 \%$ \\
\hline Transport equipment & $1.93 \%$ & $1.22 \%$ & $1.00 \%$ \\
\hline Manufacturing n.e.c. & $1.70 \%$ & $0.36 \%$ & $0.98 \%$ \\
\hline \multicolumn{4}{|l|}{ By industry: service } \\
\hline All service firms & $1.92 \%$ & $0.54 \%$ & $1.36 \%$ \\
\hline $\begin{array}{l}\text { Wholesale and retail trade; repair of } \\
\text { motor vehicles, motorcycles and } \\
\text { personal and household goods }\end{array}$ & $2.05 \%$ & $0.63 \%$ & $1.43 \%$ \\
\hline Transport, storage and communication & $1.55 \%$ & $0.26 \%$ & $0.81 \%$ \\
\hline Renting and business activities & $1.75 \%$ & $0.53 \%$ & $1.44 \%$ \\
\hline
\end{tabular}

n.e.c. not elsewhere classified

Table 9 Mean (SD) of the included firm-characteristics on the sub-sector level

\begin{tabular}{|c|c|c|c|c|}
\hline By industry for $1997-2013$ & $L$ & $K$ & $Y$ & Obs. \\
\hline Food products, beverages and tobacco & $37.08(182.0)$ & $32,360.8(318,626.1)$ & $21,098.4(117,714.1)$ & 19,990 \\
\hline Textile and leather products & $16.91(65.24)$ & $12,251.1(223,642.8)$ & $8270.2(52,256.7)$ & 8528 \\
\hline Wood and products of wood & $19.82(68.49)$ & $12,506.0(96,869.6)$ & $9410.6(36,509.4)$ & 20,709 \\
\hline Pulp, paper, paper products, publishing and printing & $32.25(129.2)$ & $43,464.4(420,069.6)$ & $22,500.1(124,612.9)$ & 29,272 \\
\hline $\begin{array}{l}\text { Coke, refined petroleum products, nuclear fuel, chemicals, rubber and } \\
\text { plastic products }\end{array}$ & $52.19(310.5)$ & $206,579.1(5,109,529.9)$ & $59,944.8(787,775.6)$ & 15,172 \\
\hline Other non-metallic mineral products & $38.71(113.6)$ & $28,140.5(117,695.4)$ & $22,460.9(71,385.2)$ & 6359 \\
\hline Basic metals and fabricated metal products & $20.29(97.31)$ & $11,703.5(164,087.7)$ & $10,898.8(78,673.7)$ & 62,809 \\
\hline Machinery and equipment n.e.c. & $39.61(161.8)$ & $33,683.6(686,939.8)$ & $24,061.0(126,788.0)$ & 31,026 \\
\hline Electrical and optical equipment & $40.33(448.3)$ & $31,016.5(650,910.4)$ & $29,143.4(485,419.4)$ & 22,369 \\
\hline Transport equipment & $108.9(809.9)$ & $138,829.1(1,806,939.1)$ & $69,128.2(613,636.4)$ & 11,767 \\
\hline Manufacturing n.e.c. & $19.32(72.18)$ & $7680.1(42,745.0)$ & $9274.7(34,293.4)$ & 20,990 \\
\hline $\begin{array}{l}\text { Wholesale and retail trade; repair of motor vehicles, motorcycles and } \\
\text { personal and household goods }\end{array}$ & $12.82(105.6)$ & $5794.8(134,237.7)$ & $6797.8(62,456.6)$ & 453,696 \\
\hline Transport, storage and communication & $22.14(360.9)$ & $31,468.2(1,270,571.5)$ & $12,831.9(251,486.8)$ & 140,661 \\
\hline Renting and business activities & $17.32(213.3)$ & $30,021.2(905,392.7)$ & $9899.9(114,398.7)$ & 325,686 \\
\hline
\end{tabular}

n.e.c. not elsewhere classified 


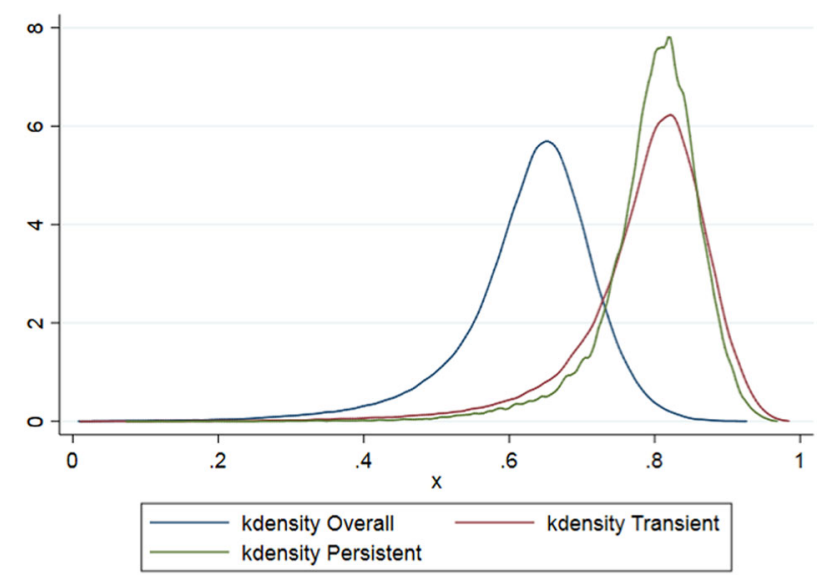

Fig. 3 Components of efficiency for the manufacturing sector

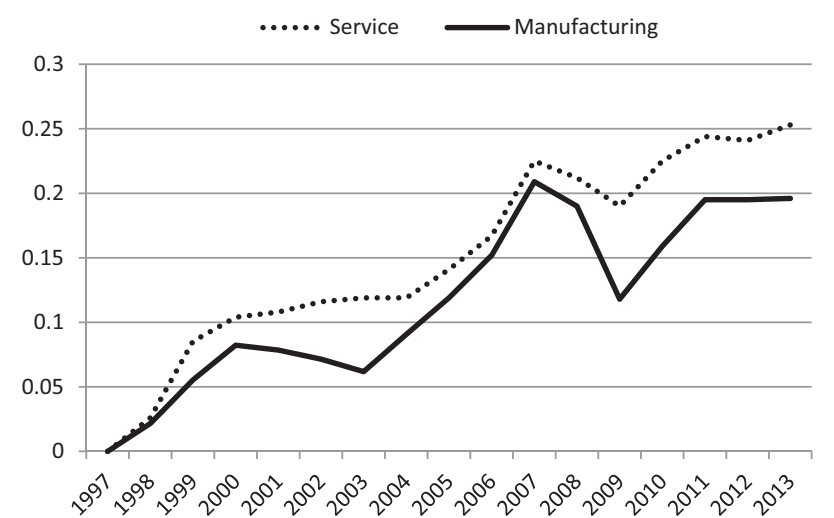

Fig. 5 Technical change measured with time dummies for manufacturing and services. Figure 5 shows TC over time measured with time dummies. This, however, is not TC in its original interpretation since these changes are clearly a result of cyclical factors. The solid line indicates that manufacturing caught-up to its previous level in ${ }^{30}$ 2011. However, the average production function is on a similar level as before the crisis, indicating that it has not caught up to its original trend. In contrast, the service sector is, visually, at the same trend as previously. This was not shown for the TFP growth since (1) no scale effect is included here, and (2) the interaction of time is not included. An interpretation of this is that TC and TFP growth are largely affected by the financial crisis, especially the manufacturing sector. From Fig. 1 , it could be observed that the aggregated value added has declined. Furthermore, Fig. 5 indicates a slowdown of growth that can have several explanations, e.g., absence of re-investment in capital or loss in competitive power in the international market. However, this is not in the scope of this study to investigate

\footnotetext{
$\overline{30}$ The differences in comparison to the previous results are due to: (1) interactions were previously included and (2) the calculation of TC of the separated period does not take the first year into account. However, the conclusion remains constant.
}

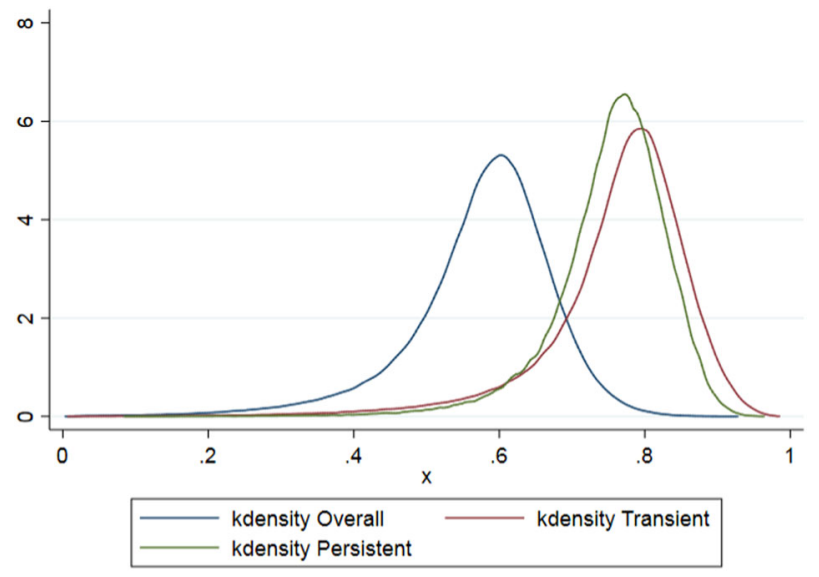

Fig. 4 Components of efficiency for the service sector

\section{References}

Ackerberg DA, Caves K, Frazer G (2015) Identification properties of recent production function estimators. Econometrica 83 (6):2411-2451

Aguiar D, Costa L, Silva E (2017) An attempt to explain differences in economic growth: a stochastic frontier approach. Bull Economic Res 69:42-65

Aigner D, Lovell CK, Schmidt P (1977) Formulation and estimation of stochastic frontier production function models. J Econ 6:21-37

Andrews D, Criscuolo C, Gal PN (2016) The best versus the rest: the global productivity slowdown, divergence across firms and the role of public policy, OECD Productivity Working Papers, 2016-05, OECD Publishing, Paris

Badunenko O, Kumbhakar SC (2017) Economies of scale, technical change and persistent and time-varying cost efficiency in Indian banking: do ownership, regulation and heterogeneity matter? Eur J Operational Res 260:789-803

Baltagi BH, Griffin JM (1988) A general index of technical change. J Political Econ 96(1):20-41

Baltagi BH, Griffin JM, Rich DP (1995) The measurement of firmspecific indexes of technical change. Rev Econ Stat 77:654-663

Battese GE, Coelli TJ (1988) Prediction of firm-level technical efficiencies with a generalized frontier production function and panel data. J Econ 38:387-399

Bauer PW (1990) Decomposing TFP growth in the presence of cost inefficiency, nonconstant returns to scale, and technological progress. J Product Anal 1:287-299

Bell A, Jones K (2015) Explaining fixed effects: random effects modeling of time-series cross-sectional and panel data. Political Sci Res Methods 3(1):133-153

Bergvall A (2002) Exchange rate regimes and macroeconomic stability: the case of Sweden 1972-1996 (No. 2000: 25). Working paper, Department of Economics, Uppsala University

Bostian M, Färe R, Grosskopf S, Lundgren T (2016) Environmental investment and firm performance: a network approach. Energy Econ 57:243-255

Carlsson B (1972) The measurement of efficiency in production: an application to Swedish manufacturing industries 1968. Swed J Econ 74(2):468-485

Caves DW, Christensen LR, Diewert WE (1982) The economic theory of index numbers and the measurement of input, output, and productivity. Econometrica 50(6):1393-1414 
Charnes A, Cooper WW, Rhodes E (1978) Measuring the efficiency of decision making units. Eur J Oper Res 2(6):429-444

Christensen LR, Jorgenson DW, Lau LJ (1973) Transcendental logarithmic production frontiers. Rev Econ Stat 55(1):28-45

Cerra V, Saxena SC (2008) Growth dynamics: the myth of economic recovery. Am Economic Rev 98:439-457

Colombi R, Kumbhakar SC, Martini G, Vittadini G (2014) Closedskew normality in stochastic frontiers with individual effects and long/short-run efficiency. J Product Anal 42:123-136

Das MK, Patra S (2016) Productivity and efficiency of public sector banks in India after the global financial crisis. IUP J Bank Manag 15:50

De Loecker J (2011) Product differentiation, multiproduct firms, and estimating the impact of trade liberalization on productivity. Econometrica 79(5):1407-1451

Diewert WE (1976) Exact and superlative index numbers. J Econ 4:115-145

Färe R, Grosskopf S, Lindgren B, Roos P (1994) Productivity developments in Swedish hospitals: a Malmquist Output Index approach. In: Charnes A, Cooper WW, Lewin AY, Seiford LM (Eds.) Data evelopment analysis: theory, methodology, and applications. Springer, Dordrecht, p 253-272

Färe R, Grosskopf S, Lundgren T, Marklund PO, Zhou W (2016) The impact of climate policy on environmental and economic performance: evidence from Sweden. Routledge, London

Filippini M, Greene W (2016) Persistent and transient productive inefficiency: a maximum simulated likelihood approach. J Product Anal 45:187-196

Filippini M, Geissmann T, Greene WH (2018) Persistent and transient cost efficiency — an application to the Swiss hydropower sector. J Product Anal 49(1):65-77

Fukao K, Kwon HU (2006) Why did Japan's TFP growth slow down in the last decade? An empirical analysis based on firm level data of manufacturing firms. Jpn Econ Rev 57:195-228

Gounder R, Xayavong V (2004) A decomposition of total factor productivity growth in New Zealand's manufacturing industries: a stochastic frontier approach. In: New Zealand Association of Economists Conference, Wellington (Vol. 30 June)

Greene W (2005a) Reconsidering heterogeneity in panel data estimators of the stochastic frontier model. J Econ 126:269-303

Greene W (2005b) Fixed and random effects in stochastic frontier models. J Product Anal 23:7-32

Greene W (2008) The econometric approach to efficiency analysis. Meas Product Effic Product Growth 1:92-250

Harris R, Moffat J (2016) The UK productivity puzzle, 2008-2012: evidence using plant-level estimates of total factor productivity. Oxf Econ Papers 69(3):529-549

Heshmati A, Kumbhakar SC (2014) A general model of technical change with an application to the OECD countries. Econ Innov New Technol 23:25-48

Heshmati A, Kumbhakar SC, Kim J (2018) Persistent and transient efficiency of international airlines. Eur J Transp Infrastruct Res 18 (2):213-238

Jondrow J, Lovell CK, Materov IS, Schmidt P (1982) On the estimation of technical inefficiency in the stochastic frontier production function model. J Econ 19:233-238

Kaldor N (1966) Causes of the slow rate of economic growth of the United Kingdom: an inaugural lecture. Cambridge University Press, London

Kapelko M, Oude Lansink A (2015) Technical efficiency and its determinants in the Spanish construction sector pre-and postfinancial crisis. Int J Strateg Prop Manag 19:96-109

Kapelko M, Oude Lansink A, Stefanou SE (2014) Assessing dynamic inefficiency of the Spanish construction sector pre-and postfinancial crisis. Eur J Operational Res 237:349-357
Kapelko M, Oude Lansink A, Stefanou SE (2017) The impact of the 2008 financial crisis on dynamic productivity growth of the Spanish food manufacturing industry. An impulse response analysis. Agric Econ 48:561-571

Kim S, Han G (2001) A decomposition of total factor productivity growth in Korean manufacturing industries: a stochastic frontier approach. J Product Anal 16:269-281

Kim S, Shafi'i M (2009) Factor determinants of total factor productivity growth in Malaysian manufacturing industries: a decomposition analysis. Asian Pac Econ Lit 23:48-65

Krugman PR (1997) The age of diminished expectations: US economic policy in the 1990s. MIT Press, Cambridge, MA

Kumbhakar SC (1987) The specification of technical and allocative inefficiency in stochastic production and profit frontiers. J Econ 34:335-348

Kumbhakar SC (1990) Production frontiers, panel data, and timevarying technical inefficiency. J Econ 46:201-211

Kumbhakar SC (2000) Estimation and decomposition of productivity change when production is not efficient: a panel data approach. Econom Rev 19:312-320

Kumbhakar SC, Heshmati A (1995) Efficiency measurement in Swedish dairy farms: an application of rotating panel data, 1976-88. Am J Agric Econ 77:660-674

Kumbhakar SC, Heshmati A (1996) Technical change and total factor productivity growth in Swedish manufacturing industries. Econom Rev 15:275-298

Kumbhakar SC, Lien G, Hardaker JB (2014) Technical efficiency in competing panel data models: a study of Norwegian grain farming. J Product Anal 41:321-337

Kumbhakar SC, Wang H, Horncastle AP (2015) A practitioner's guide to stochastic frontier analysis using Stata. Cambridge University Press, New York

Kumbhakar SC, Lien G (2017) Yardstick regulation of electricity distribution-disentangling short-run and long-run inefficiencies. Energy J 38:17-37

Kumbhakar SC, Parmeter CF, Zelenyuk V (2017) Stochastic Frontier Analysis: Foundations and Advances, Working Papers 2017-10, University of Miami, Department of Economics

Lai HP, Kumbhakar SC (2018) Endogeneity in panel data stochastic frontier model with determinants of persistent and transient inefficiency. Econ Lett 162:5-9

Lee YH, Schmidt P (1993) A production frontier model with flexible temporal variation in technical efficiency. In: Fried H, Lovell K, Schmidt S (Eds.) The measurement of productive efficiency: techniques and applications. Oxford University Press, Oxford, UK, p 237-255

Lovell CK (1996) Applying efficiency measurement techniques to the measurement of productivity change. J Product Anal 7:329-340

Levinsohn J, Petrin A (2003) Estimating production functions using inputs to control for unobservables. Rev Economic Stud 70 (2):317-341

Lundgren T, Marklund PO, Samakovlis E, Zhou W (2015) Carbon prices and incentives for technological development. J Environ Manag 150:393-403

Lundgren T, Zhou W (2017) Firm performance and the role of environmental management. J Environ Manag 203:330-341

Meeusen W, van Den Broeck J (1977) Efficiency estimation from Cobb-Douglas production functions with composed error. Int Econ Rev 18(2):435-444

Mundlak Y (1961) Empirical production function free of management bias. J Farm Econ 43:44-56

Nishimizu M, Page JM (1982) Total factor productivity growth, technological progress and technical efficiency change: dimensions of productivity change in Yugoslavia, 1965-78. Econ J 92:920-936 
OECD (2015) OECD compendium of productivity indicators 2015. OECD Publishing, Paris. 10.1787/pdtvy-2015-en

Oh D, Heshmati A, Lööf H (2012) Technical change and total factor productivity growth for Swedish manufacturing and service industries. Appl Econ 44:2373-2391

Olley GS, Pakes A (1996) The dynamics of productivity in the telecommunications equipment industry. Econometrica 64(6):1263

Papagiannis GD (2014) Measurement of efficiency in Greek banking industries in the light of the financial crisis. Eur Res Stud 17:19

Park KH, Weber WL (2006) A note on efficiency and productivity growth in the Korean banking industry, 1992-2002. J Bank Financ 30:2371-2386

Pires JO, Garcia F (2012) Productivity of nations: a stochastic frontier approach to TFP decomposition. Econ Res Int 2012

Pitt MM, Lee LF (1981) The measurement and sources of technical inefficiency in the Indonesian weaving industry. J Dev Econ 9:43-64

Schmidt P, Sickles RC (1984) Production frontiers and panel data. J Bus Econ Stat 2:367-374
Shee A, Stefanou SE (2015) Endogeneity corrected stochastic production frontier and technical efficiency. Am J Agric Econ 97 (3):939-952

Solow RM (1957) Technical change and the aggregate production function. Rev Econ Stat 39(3):312-320

Sun K, Kumbhakar SC, Tveterås R (2015) Productivity and efficiency estimation: a semiparametric stochastic cost frontier approach. Eur J Operational Res 245:194-202

Tsionas EG, Kumbhakar SC (2014) Firm heterogeneity, persistent and transient technical inefficiency: a generalized true random effects model. J Appl Econ 29:110-132

Van Beveren I (2012) Total factor productivity estimation: a practical review. J Econ Surv 26(1):98-128

Wang HJ, Schmidt P (2002) One-step and two-step estimation of the effects of exogenous variables on technical efficiency levels. J Product Anal 18:129-144

Zheng J, Wang Z, Shi J (2008) Industrial productivity performance in Chinese regions (1987-2002): a decomposition approach. J Chin Econ Bus Stud 6:157-175 